was observed only in the crossed pyramidal tracts in the entire cord and its upper limit was at the level of the decussation in the uppermost segment of the cervical portion. Clinically the patient presented a typical picture of spastic paraplegia of 20 years' duration. Dr. Gordon discussed the pathogenesis of the affection and arrived at the conclusion that very probably the disease belongs to the abiotrophies on the order of Friedreich's ataxia, syringomyelia and others. An interesting etiological element in Dr. Gordon's case is the history of a persistent and prolonged exposure to cold. The patient worked in an ice plant since the age of I 2 and at 16 the first symptoms made their appearance. He died at 34 .

\title{
CHICAGO NEUROLOGICAL SOCIETY
}

December 20, I9II

\section{PRESENTATION OF A HISTORY AND A BRAIN OF A CASE OF HYPOPHYSEAL DISEASE}

By Geo. McBean, M.D.

\begin{abstract}
Miss S. E. K. Age 36 . Refused to give history as it might prejudice diagnosis.
\end{abstract}

Condition March I4, I9Io. Height 5 feet Io inches, weight I60 pounds. Eyes rather prominent, left pupil larger than right. Right eye convergent, outward rotation limited. Vision right Io/Io, left 8/10. Some metamorphosis in both eyes. Choked disc + I D right, $+2 \mathrm{D}$ left. Fields slightly contracted, color fields partly overlapping, natural blind spot slightly enlarged. Post nasal examination shows small polypus in right nares coming from interior of sphenoidal sinus, which was found diseased, a tentative diagnosis of optic neuritis secondary to nasal sinus disease with paresis of the right external rectus muscle, an operation advised.

March I6 at operation the sphenoidal sinus was found packed with polypoid mass, curetted, and examined. Considered carcinoma and granuloma by different men. Vision and diplopia much improved. After making the diagnosis the patient gave the history which had been previously refused. She had had amenorrhea for eight years without apparent cause, and had gained about fifty pounds in the first year. About August, I909, she had had an acute thinitis, and all the symptoms had apparently dated from that time. The diplopia of recent development was the most annoying symptom. There was history of frequent, transitory glandular enlargements in various parts of the body, especially the axillz. There was also a transient, non-inflammatory edema of the ocular conjunctiva which appeared occasionally and lasted a few hours. Within three weeks after the operation the sinus began to fill up again. Drs. Shambaugh, Brown, Fish and Lewy in consultation urged further operative measures, which were refused. November I8, I9Io, patient showed a paracentral scotoma in the left eye, vision r. 6/10, 1. 6/5. Mass was projecting from the open sphenoidal sinus. Patient went to California. In June, I9II, patient constlted a physician for severe headaches accompanied by mental disturbances, transitory loss of memory, and increasing blindness. K. I. had a remarkable effect, clearing up the pain at once. February 2I Dr. McBean had a Wassermann test made which was reported moderately positive and the patient was put on larger doses 
of K. I. and daily intramuscular injections of mercury. Skiagraphs showed an enlarged sella turcica. Dr. Grinker in consultation made the diagnosis of tumor in the region of the sella turcica with increased intracranial pressure. Patient's vision at the time was further reduced. The form field was not contracted much but the color fields showed a bitemporal hemichromatopsia. The scotomata were larger than in November. The patient was sent to Dr. Cushing in Baltimore, April I9, I9r r, from whom the following notes were received:

"There is evidence of a large growth or hyperplasia which has done more than merely occupy the sellar region; which has broken through into the cranial fossa itself, as shown by the general pressure symptoms: Bilateral choked disc +2 r., +3 1.; primary optic atrophy; central scotomata; vision low in both eyes. There is increased carbohydrate tolerance; subnormal temperature for some years; low blood pressure; adiposity; dry skin. No acromegalic facies and no definite bone changes in the hands. Wassermann negative.

"Operation April 20, I9II, sublabial approach, submucous resection of the nasal septum. Removal of large portion of growth from sphenoid sinus and distended sella turcica."

May I 7 , I9I I, she returned to Chicago practically blind from the large central scotomata. During the summer the vision failed completely, from secondary atrophy of the optic nerve. The lapses in memory became more frequent as did the headaches.

She entered the hospital August io. Headaches became very severe. About September 15 the pain studdenly ceased and the mind cleared remarkably, probably from a leak of cerebrospinal fluid. She was comparatively well for a month, then the pain returned and she died October 20.

The post-mortem by Dr. Chislett showed a large tumor in the sella turcica adherent to the bone, projecting into the sphenoidal sinuses and involving the left lateral ventricle, which it entered from below, not through the foramen of Monro.

\section{PRESENTATION OF THE CASE OF FACIAL PARALYSIS WITH INVOLVEMENT OF THE STYLO-HYOID AND POSTERIOR BELLY OF THE DIGASTRIC}

By R. C. Hamill, M.D.

The patient is forty years old, male. Chancre. I8 years ago with secondaries, practically no treatment. Six years ago, exposed to the cold, severe pain down the right side of the neck every night for a week then woke one morning with the right face paralyzed. After about three weeks began to improve and about two months after was practically as he is at present. There is paresis of the upper and lower facial branches, no loss of taste on the anterior two thirds of the tongue can be determined. Hearing normal. General examination normal. Thyroid cartilage lies at rest $I / 3$ in. to the left of the median line. When the patient swallows or talks the excursion seems to be practically vertical. The right half of the tongue is slightly broader than the left and both when at rest and protruded is decidedly lower than the left. It protrudes in the midline.

The spinal fluid showed two cells to the cm., and Wassermann was negative whereas it was positive in the blood. 